Naphtha mischt sich nicht mit Wasser und Methylalkohol, leicht mit absolutem Alkohol, Schwefelkohlenstoff und dem gewöhnlichen Petroleum. Gewöhnlicher Aether bringt eine Trübung hervor, wahrscheinlich durch einen Wassergehalt, ebenso gewöhnlicher Alkohol. Fette und flüchtige Oele mischen sich leicht mit Naphtha.

Schwefel und Phosphor lösen sich etwas darin. Talg, Stearinsäure, Palmöl, Walrath, Wachs und Paraffin lösen sich nur in der Wärme leicht darin. Kautschuk wird weich, bläht sich auf und löst sich endlich wie in Schwefelkohlenstoff. Asphalt und venetianischer Terpentin lösen sich in der Wärme gut in Naphtha; Colophonium, Mastix, Dammar und Pech nur schwierig; Ambra, Copal und Gummilack fast gar nicht.

Naphtha besteht aus sehr verschiedenen Körpern. Die Bildung von Nitrobenzin lässt auf Benzin zurückschliessen, das immer nur in geringer Menge vorhanden ist. Bei $100^{\circ} \mathrm{C}$. erhielt man 48,6 Proc. eines Oeles von 0,70 , bei $200^{\circ}$ C. 45,7 Proc. Oel von 0,73 , bei mehr als 2000C. 5,7 Proc. Oel von 0,80 spec. Gew.

Beim Eindampfen zur Trockne binterbleibt ein geringer, kohliger Rückstand.

Das erste Destillationsproduct, welches die grösste Menge des amerikanischen Petroleums bildet, nennt $W$ i ederhold Petroleum aethereum. (Journ. de Pharm. d'Anvers. Juin. 1863.)

Dr. Reich.

\title{
Untersuchung mehrerer flüchtiger Brennöle auf ihre Feuergefährlichkeit.
}

In Folge eines Auftrages der Direction der Feuerversicherungs - Anstalt der bayerischen Hypotheken- und Wechselbank, die in neuerer Zeit in Gebrauch genommenen flüchtigen Brennöle auf ihre Feuergefährlichkeit zu prüfen, namentlich das robe und gereinigte Petroleum, Photogen, Schieferöl, Solaröl und Camphin, wurde von Witts tein eine genaue Untersuchung darüber angestellt. Das praktische Resultat sämmtlicher Versuche ist in folgenden Sätzen enthalten.

1) Das rohe Petroleum und das Schieferöl müssen hinsichtlich ihrer Feuergefährlichkeit mit dem Weingeist in eine Classe gestellt werden.

2) Das Photogen und Camphin sind nicht so feuergefahrlich als jene, reihen sich aber den zwei ersteren an. 
3) Das Solaröl gehört in die Classe der fetten Oele. (Wittst. Vierteljahr'sschr. Bd. 12. 3.)

$B$.

Dr. Hirtzel in Leipzig hat die Wittstein'schen Resultate als ungenaue und einseitige angegriffen. (Rossmässler's "Aus der Heimath".)

L.

\section{Darstellung von Nitrobenzol.}

Bei Darstellung des Nitrobenzols aus käuflichem Benzol mit rauchender Salpetersäure hört man allgemein die Klage, dass die ersten Portionen des Destillats einen höchst unangenehmen Beigeruch haben, welcher von einem Gehalte an schwefelhaltigem Oele im käuflichen Benzol herrührt. Um nun ein künstliches Bittermandelöl von gutem Geruche zu erhalten, muss das käufliche Benzol nach Dr. Vohls Angabe der Destillation unterworfen werden, bis der Siedepunct auf 82 bis 8.30 gestiegen ist; nan hat alsdann im Destillate den schwefelhaltigen Körper und im Rückstande ziemlich reines Benzol. Dieses wird nun nach der bekannten Weise nitrirt, alsdann mit Wasser 3-4 mal gewaschen und, nachdem man zuletzt einige Procente kohlensaures Natron hinzugesetzt hat, um die letzten Spuren der Salpetersäure zu neutralisiren, mit Wasserdampf abgeblasen. Die ersten Portionen des Destillats enthalten nur noch Spuren des schwefelhaltigen Oels, das andere nachfolgende Destillat ist reines Nitrobenzol.

Um keinen Verlust durch die Löslichkeit in Wasser zu erleiden, ist der Apparat so eingerichtet, dass das mit ubergehende Wasser in den Dampfentwickler zurückfliesst und so mit einer geringen Quantität Wasser unbegrenzte Mengen Nitrobenzol abdestillirt werden können. Mit 100 Gewichtstheilen Wasser, die in Dampf von atmosphärischer Spannung verwandelt werden, kann man 16,178 Gewichtstheile Nitrobenzol destilliren. Die in dem Wasser uufgelöste Nitrobenzolmenge beträgt 0,183 Proc. Durch Kochsalz lässt sich das Nitrobenzol aus dem Wasser abscheiden. Auch das Nitrotoluol, Nitrocumol etc. werden gerade so wie oben angeführt dargestellt. (Dingl. polyt. Journ. Bd.167. - Chem. Centrbl. 1863. 55.) B.

\section{Verfälschung des Bittermandelöles durch Bssence de Mirbane.}

Man erkennt nach Maisch die Verfälschung durch die Reaction einer alkoholischen Kalilösung auf Nitroben- 